Bangladesh J. Zool. 42(2): 217-225, 2014

\title{
SOCIAL INTERACTIONS OF HANUMAN LANGUR (SEMNOPITHECUS ENTELLUS) AT KESHABPUR AND MANIRAMPUR OF JESSORE DISTRICT OF BANGLADESH
}

\author{
Md. Mahabub Alam, M. Firoj Jaman*, Md. Mahedi Hasan, Md. Mokhlesur \\ Rahman, Shayer Mahmood Ibney Alam ${ }^{1}$ and Ummay Habiba Khatun ${ }^{1}$ \\ Department of Zoology, University of Dhaka, Dhaka-1000, Bangladesh
}

\begin{abstract}
Social interactions of Hanuman langurs (Semnopithecus entellus) were studied from August, 2013 to July, 2014 at Keshabpur and Manirampur Upazila, Jessore, Bangladesh. The study was mainly based on direct field observations from dawn to dusk and data was collected through focal animal sampling in 10minutes duration. During the study period seven groups of Hanuman langurs were found in urban and rural habitats. Eight behavioral activities like resting, feeding, grooming, moving, parental care, playing, submission and aggression were recorded. They interacted with each other through grooming, parental care, playing, submission and aggression. Social interactions varied in urban and rural habitats. Aggression was mostly observed in rural habitat and generally showed by the males. Adults were engaged in playing to encourage infants, juveniles and sub-adults. Significant seasonal variation of grooming was observed between age classes. Females were engaged more in grooming and parental care than males. Allomothering was also observed within a group. More submission was received by dominant males within a group. Langurs of focal groups spent $41.04 \%$ of their total activity budget in resting which was the highest activity followed by $33.75 \%$ in feeding, $11.73 \%$ in grooming, $4.87 \%$ in moving and $8.61 \%$ time for other activities.
\end{abstract}

Key words: Hanuman langur, social interactions, grooming and allomothering

\section{INTRODUCTION}

Primate societies are generally structured organizations with fairly clear social bonding that determine the patterns of interactions between different classes of individuals comprising these societies (Lal and Rajpurohit 2010). There are two important factors like kinship and dominance rank that regulate group cooperation and competition among individuals in typical cercopithecine societies (Oates 1987). Individual primates can occasionally alter their usual patterns of interactions, especially when the social or ecological environment makes such advantageous behavioral flexibility (Cheney and Seyfarth 1990).

Social interactions of Hanuman langurs are displayed through grooming, aggression, submission, playing, mating, parental care. They are engaged in grooming due to pick up debris and insect from their body to keep them neat

*Author for correspondence: <mfjaman@yahoo.com>.1Department of Zoology, Jagannath University, Dhaka-1100, Bangladesh. 
and clean as well as to meet up the demand of protein as insects are considered good source of that nutrient (Rahman 2012). In grooming, sometimes more than one individual are associated where they interact with each other. However, high-ranking females give out and receive more grooming than the low ranking individuals (Borries et al. 1994). In addition, males are usually groomed more often by the females and low ranking individuals (Ahsan and Khan 2006). Intersex relationships are usually positive than intrasex that means male-female interactions are beneficial. Females within a group are maternally related (Mohnot and Srivastava 1992), female memberships are stable, but in larger groups it is less true (Newton 1994, Koenig 2000). They give birth and care for their offspring. Alloparenting occurs among langurs starting when the infants reached at two years of age. Dominance rituals are most common among highranking langurs (Rajpurohit and Rajpurohit 2005). In this case males are the highest social rank, engaged themselves in displaying, vocalizing, fighting for dominance and maintaining territory (Ahsan and Khan 2006). The father of the most offspring is the highest ranking male followed by the next-ranking males (Launhardt et al. 2001). The highest ranking of the invaders subsequently installs himself as the new resident male of the invaded troop, and this is followed by the removal of weaned male juveniles (Rajpurohit and Rajpurohit 2003). Sometimes infant, juvenile and sub-adults are associated with false fighting, running, jumping for playing. Feeble langurs show submissive behavior towards their high ranking individuals. Within a group, aggressive and submissive interactions are more often between high-ranking members (Rajpurohit and Rajpurohit 2005). Visual and tactile threat, gestures, displacement, charges and chases and physical attacks are different moods of aggression within a group (Bogges 1976).

In the Indian subcontinent the Hanuman Langur is a most widely distributed animal species of the non-human primate species (Roonwal and Mohnot 1977) and also possibly in Afghanistan (Brandon-Jones 2004). They are usually arboreal, inhabiting forest, open lightly wooded habitats and urban areas on the Indian subcontinent. Langurs live in groups, numbering 40-60 (Roberts 1997). It has been reported that the sub-species Semnopethicus entellus entellus (Dufresne 1797) occur only at Jessore, Jhenaidah, Chuadanga, Meherpur and Kushtia Districts in Bangladesh (Ahsan and Khan 2006). Now they are considered as Critically Endangered (IUCN 2000) and struggling for their existence within this human dominated landscape. Special attention is needed to conserve them. The main objective is to focus on Hanuman langurs to get baseline data which is needed for determining positive and negative interaction among them through studying their social interactions. 


\section{MATERIAL AND METHODS}

Study area and subject: This study was conducted in the Keshabpur $\left(22^{\circ} 54^{\prime} 29.71^{\prime \prime} \mathrm{N}, 8^{\circ} 13^{\prime} 9.18^{\prime \prime} \mathrm{E}\right)$ and Manirampur $\left(23^{\circ} 1^{\prime} \mathrm{O}^{\prime \prime} \mathrm{N}, 8^{\circ} 14^{\prime} \mathrm{O}^{\prime \prime} \mathrm{E}\right)$ subdistricts of Jessore district located in southwestern Bangladesh. According to the census 2011 these two study sites covered $703.25 \mathrm{sq} \mathrm{km}$ (271.52 sq miles) with a human population density of 953 individuals per square kilometer. Annual average maximum temperature in these areas was $37.1^{\circ} \mathrm{C}$ in June while the minimum was $11.2{ }^{\circ} \mathrm{C}$ in January. The accumulative annual rainfall was $1537 \mathrm{~mm}$ during the study period.

All focal subjects were individually recognized and classified into six categories, based on age-group with regards to sexual maturity: adult male $(>5$ years), adult female (> 2.9 years), sub-adult male (2-5 years), sub-adult female (2-3 years), juveniles (9 months-2 years) and infant (0-8 months) (Gron 2008). Adults are able to reproduce and show reproductive behavior while sub adults are unable to reproduce, but display mating activities during the breeding period.

Observations and sampling protocol: We collected data from August 2013 to July 2014 in the form of 10-minute continuous focal animal samples (Altman 1974, Martin and Bateson 2007). Individual identification of langurs was conducted before collecting data. Assessment of the environmental condition was conducted before collecting data. Study area was divided into urban and rural habitats where seven groups of langurs were observed. Urban habitat included upazila parisad, upazilla health complex and rural habitat included Ramchandrapur, Brammakati and Mujgunni in Keshabpur and Manirumpur respectively. Two groups were observed from two habitats. Three days were spent per month, each day we collected 48 focal samples in a study group (3 days $\times 48$ focals $\times 12$ months $=1728$ focal samples $=288$ hours). The study period was divided into three seasons; rainy (July-October), winter (NovemberFebruary) and summer (March-June). We sampled all focal subjects (except juveniles and infants) equally across the three seasons.

Eight behavioral categories were recorded which are as follows: resting, feeding, grooming, parental care, moving, playing, submission and aggression. One day prior to the commencement of data collection, the trees on which the focal group roosted were recorded. This strategy accelerated to start observation next day as they go away from the roosting site very early in the morning. To supplement the field data, a number of knowledgeable local people were also interviewed.

Data analysis: The data were organized more or less equally among all focal subjects across the time period of day, month and season in excel spreadsheet. 
Seasonal variation of grooming was examined using t-test. Exact $\mathrm{P}$ values for each analysis were presented in the results. All data were analyzed using MSExcel and SPSS (version 16).

\section{RESULTS AND DISCUSSION}

Total activity budget of langurs: During study period, it was observed that langurs showed their daily behavioral activities like resting, feeding, grooming, parental care, moving, playing, aggression and submission which were started from early in the morning by the call of dominant male "whoops".

Out of their activity budget they spent the highest $41.04 \%$ time for resting, followed by $33.75 \%$ time for feeding, $11.73 \%$ for grooming, $4.87 \%$ for moving, $2.86 \%$ for playing, $2.75 \%$ time for parental care and remaining $3.0 \%$ time was spent for submission and aggression.

We observed that langurs mostly consumed leaves, fruits, buds, barks, flowers and seed of different plant species. A total of 30 species of plants they consumed during summer, 25 species in winter and 22 in rainy season. They were also provided provisioned food like banana, nut and bread by the Forest Department, Bangladesh specially in the urban areas.

Social interactions of langurs in different habitats: All members within a group interacted with each others. It was observed that social interactions of langurs occurred through grooming, parental care, playing, submission, aggression and mating. Considering social interaction they spent $34.2 \%$ time in grooming followed by $23.4 \%$ time in playing, $16.3 \%$ in parental care, $14.0 \%$ in aggression and $12.6 \%$ in submission. The social interactions of langurs varied in urban and rural habitats. We found that the urban habitat was more preferable to the rural habitat in social interactions. They spent more or less similar amount of time in two different habitats except grooming and parental care which were more frequent in the urban group (Table 1).

Table 1. Percentage of interactive behaviors of Hanuman langurs in two different habitats

\begin{tabular}{lrrr}
\hline \multirow{2}{*}{ Behavior } & \multicolumn{3}{c}{ Time spent (\%) } \\
\cline { 2 - 4 } & Rural & \multicolumn{1}{c}{ Urban } & Overall \\
\hline Grooming & 32.3 & 36.1 & 34.2 \\
Playing & 24.4 & 22.5 & 23.4 \\
Aggression & 15.4 & 12.5 & 14.0 \\
Submission & 13.1 & 12.1 & 12.6 \\
Parental care & 15.2 & 17.3 & 16.3 \\
\hline
\end{tabular}

Cheney (1987) reported that the Majority of primate species live in groups and interacts with other members within the group. There are numerous potential benefits to sociality and social interactions, including increased 
protection from predators, making good use of food resources, easy access to mate and collective rearing of offspring's (Rajpurohit and Rajpurohit 2005). Individuals interacting with each others share scarce resources like food, water and mates (Walter and Seyfarth 1987). The present study revealed that langurs interacted with each other to get such kind of benefits. Langurs accomplished their social interactions where food sources and resting sites were available. In the urban habitats there are many favorable roosting sites for langurs where they provisioned with nutrient rich foods provided by the Forest Department. People in the urban habitats are more tolerable and adapted to co-existence in the same habitat and sharing the same food resources. Moreover, some visitors adjacent to the local administrative office offer different food items resulting less aggression. Rural habitat was more susceptible to langurs as people showed aggressiveness because langurs in this habitat largely rely on cultivated crops and seasonal fruits.

Seasonal variation of grooming between adults and sub adults: Grooming behavior between adults and sub adults appeared to be neutral and peaceful. Season was a factor that had effect on grooming. Grooming is an activity which depends on environmental condition. We found significant seasonal differences of grooming behavior of age classes (adult; $\mathrm{t}=33.63, \mathrm{df}=2, \mathrm{P}=0.001$ and sub adult; $\mathrm{t}=27.69$, $\mathrm{df}=2 \mathrm{P}=0.001$ ). It was observed that grooming behavior of langurs was higher in rainy season than the other two seasons. Grooming was less frequent during high temperature in dry season (Fig. 1). However, grooming is related to food availability, seasonal variations and environment (Bartlett 2003). During summer and winter seasons while foods are available langurs spent more time in feeding and resting and less time in grooming. Grooming was frequently observed during rainy season due to moderate environment.

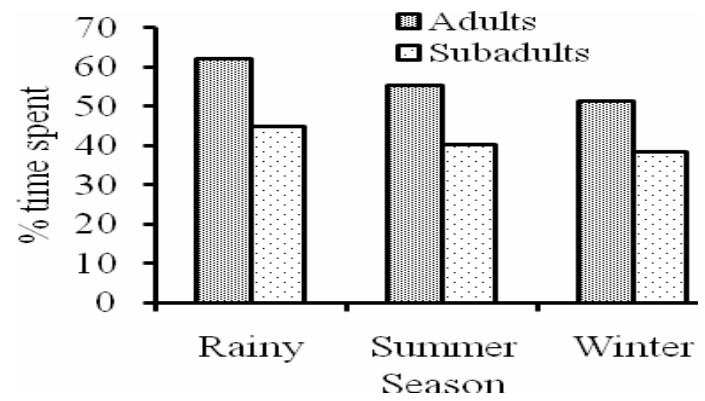

Fig. 1. Seasonal variation of grooming between adults and sub-adults langur (Semnopithecus entellus).

Grooming behavior of adult female with others age-sexes: Mainly two types of grooming behavior were noted: allogrooming and autogrooming. Allogrooming 
was mostly observed between age-sex classes. Grooming behavior varied between different age-sex classes among langurs. It was observed that adult female groomed and receive groom more than other age-sex classes within a group. We also found that female-female grooming was higher within a group. The grooming relationships between females were very strong. No aggressive behavior was found among them during grooming. Peaceful relationships were also maintained by males during grooming. Occasionally males rushed towards females but did not attack them (Fig. 2).

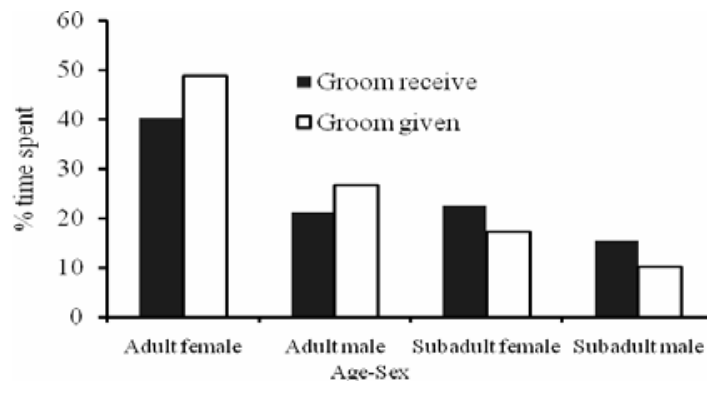

Fig. 2. Grooming behavior of female langur (Semnopithecus entellus) with other age-sex classes.

Grooming is one of the important characteristic of social interaction in which hands, lips and tongue are used to pick up ectoparasitic insect and clean debris from body for feeding and hygienic purposes (Kurland 1977). Grooming builds proximity, reinforces social structures and allowing sympathy among individuals within a group (Parr et al. 1997). Grooming between females tends to be friendly as they do various activities with each together, such as foraging, traveling, greeting and resting. Allogrooming is the non- agonistic interactions which indicate the closeness among the individuals (Ahsan 1994). Like other Primates, langurs exchange allogrooming for six accesses to food shares (De Waal and Yoshihara 1983) or to reproductive access to mates. Dominant males are engaged in allogrooming to ensure protection during violent encounters, reconciliation of conflict within groups and conciliate rivals within a hierarchy (Foster et al. 2009). Similar social interaction was observed in Hanuman langur during study period.

Parental care: It was observed that stronger relationship was made between mother and infants within a group. Infants were nursed, groomed and carried by the mother. When infants could not cross long distance, the mother came and quickly picked in its leap and crossed. Allomothering was also observed where infant was transferred to their allomother by the real mother.

Parental care is the social interaction among females and the infants. Sugiyama (1965) studied that infants spend their mothers' chests for their survival as they cannot move independently where they mostly suckle or sleep. 
Present study reveals that parental care is prominent among langurs where mother supports their infants from predators, natural calamities and from being infanticide. Infants are also weaned for the physical development

Playing: Playing is the characteristic behavior of infants and juveniles. Sometimes sub-adults showed this behavior. They engaged in false grooming, fighting, running, jumping and moving in open or semi open field, branches of trees or ground to accomplish their play. Adults within the group also played to encourage them. Play facilitates the social development within a group (Roonwal and Mohnot 1977). Play is considered as entertainment which develops communication skills and refreshes the animal. Play also related to physical development as they move, jump, rapid climb, wave of arms during playing.

Submission: One dominant alpha male maintained the entire group. The individual who were small or less strong than other individuals, showed submissive behavior towards high ranking individuals. Adult males engaged more in submission than any other individuals within a group. Submissive interaction is more often between high-ranking members within a group (Rajpurohit and Rajpurohit 2005). Present study reveals that dominant male receive more submission from the individuals within the group. Submissive interaction reduces the social conflicts which subsequently build a strong social bond among them.

Aggression: During the study period langurs showed different types of aggression such as threat, chase and fight. It was observed that the most aggressive behavior was shown by the adult males over other individuals within the group which varied to particular situation like food and mate. Social hierarchies and aggression exist for all group types (Srivastava and Mohnot 1992). In this study, aggression is observed by the high-ranking male's interaction for food and mate specially when the low ranking male mate with the female.

Mating: Mating of langur was generally observed between an adult male (alpha male) and an adult female. Female signaled the male by head shaking, dropping her tail on the ground to accomplish it. Mating was disturbed for a moment by other females and sub adult in the group. Mating is considered to be an important activity to perform sexual desire. Similar phenomenon was observed by Jay (1965) in case of Hanuman langur at Dharwar, India. It was observed that members within a group were engaged in sexual embracement to increase the population as well as to exist in the universe.

In conclusion, the Hanuman langurs reside mainly in Keshabpur and Manirumpur Upazilas in the Jessore district of Bangladesh. Concerning their social interactions, female-female grooming was higher than others within a 
group as they do various activities like foraging, share food resources, travelling, greeting and resting. Present study revealed that parental care was prominent among infants and mother as well as others females within a group. Aggression was mainly observed due to foods, mate and space by males within a group. Submissive behavior was showed by the low ranker to the high ranker to maintain hierarchy as well to share scarce resources. It is concluded that feeding can have effect on their interactions. Thus we can say that through studying social interactions of langurs we can know their behavior and subsequently measures can be taken to conserve them from their critically endangerment.

Acknowledgements: At first we express unending gratefulness to the Almighty Allah for blessing us in all aspects of life. We wish to express our deep gratitude to Dr. MA Howlader, Chairman and Professor, Department of Zoology, University of Dhaka for his kind permission and for providing all facilities in the Wildlife Laboratory. We are grateful to the World Bank and Forest Department, GoB, as the study was partially supported by them through the project "Strengthening Regional Co-operation for Wildlife Protection Project (SRCWPP)".

\section{LITERATURE CITED}

AHSAN, M. F. 1994. Behavioral ecology of the hoolock gibbon (Hylobates hoolock) in Bangladesh. Unpubl. Ph.D. thesis, University of Cambridge, Cambridge. 446 pp.

AHSAN, M.F. and KHAN, M.A.R. 2006. Eco-ethology of the common langur Semnopithecus entellus (Dufresne) in Bangladesh. Univ. J. Zool. Rajshahi Univ. 25: 3-10.

ALTMAN, J. 1974. Observational study of behaviour. Sampling methods. J. Behav. 49: 227-267.

BARTLETT, T.Q. 2003. Intragroup and Intergroup Social Interactions in White-Handed Gibbons. Int.J.Primatol. 24(2):239-259.

BOGGESS, J.E. 1976. Social behavior of the Himalayan langur (Presbytis entellus) in eastern Nepal. Ph.D dissertation, University of California, Berkeley. 247p.

BORRIES, C., SOMMER, V. and SRIVASTAVA, A. 1994. Weaving a tight social net: allogrooming in free-ranging female langurs (Presbytis entellus). Int. J. Primatol.15(3): 421-443.

BRANDON-JONES, D. 2004. A taxonomic revision of the langurs and leaf monkeys (Primates: Colobinae) of South Asia. Zoo's Print 19(8): 1552-1594.

CHENEY, D. L. and SEYFARTH, R. M. 1990. How Monkeys See the World, University of Chicago. Press, Chicago.

CHENEY, D.L. 1987. Interactions and relationships between groups. In: Primate Societies (Ed., Smuts, B.B., Wrangham, R.W., Cheney, D.L., Struhsaker, T.T. and Seyfarth, R.M.) University of Chicago Press, Chicago. pp. 267-281.

DE WAAL, F. B. M. and YOSHIHARA, D. 1983. Reconciliation and redirected affection in Rhesus monkeys. Behav. 85(3): 224-241.

DUFRESNE, P. 1797. Sur une nouvelle espece de singe, Park. Dufresne (Descripition dune nauvelle spece de guenon, sous le nom d antelle). Bulleten de societies d philo mathique paris. 1: 7: 49. 
FOSTER, M.W., GILBY, I.C., MURRAY, C.M., JOHNSON, A., WROBLEWSKI, E.E., and PUSEY, A.E. 2009. Alpha male chimpanzee grooming patterns: Implications for dominance "Style". Am. J. Primatol. 71(2): 136-144.

GRON, K. 2008. Gray langur Semnopithecus (On-line). Accessed July 28, 2010 at http://pin. primate.wisc.edu/factsheets/entry/graylangur.

IUCN. 2000. Red Book of Threatened Mammals of Bangladesh. IUCN Bangladesh. 71 p.

JAY, P.1965. The common langur of North India. In: Primate Behavior. (Ed., Devore, I.) Field studies of Monkey and apes. Holt Rinehart and Winston, New work, USA. Pages 197-249.

KOENIG, A. 2000. Competitive regimes in forest-dwelling Hanuman langur females (Semnopithecus entellus). Behav. Ecol. Sociobiol. 48(2): 93-109.

KURLAND, J. A. 1977. Kin selection in the Japanese monkey. Contributions to Primatology.12: 1-8.

LAL, D. and RAJPUROHIT, L.S. 2010. Aggressiveness and the intensity of provisioning (artificial feeding) hanuman langur around Jodhpur (Rajasthan). The Bioscan. 5(2): 259-262.

LAUNHARDT, K., BORRIES, C., HARDT, C., EPPLEN, J.T. and WINKLER, P. 2001. Paternity analysis of alternative male reproductive routes among the langurs (Semnopithecus entellus) of Ramnagar. An. Behav. 61(1): 53-64.

MARTIN, P.R. and BATESON, P.P.G. 2007. Measuring behavior: An introductory guide. Cambridge University press, Cambridge. 176 p.

MOHNOT, S.M., SRIVASTAVA, A. 1992. Evolution of langurs' social organization. Primate Report. 34: 53-63.

NEWTON, P. 1994. Social stability and change among forest Hanuman langurs (Presbytis entellus). Primates. 35(4): 489-498.

OATES, F.J. 1987. Food distribution and foraging behaviour. In: Primate Societies (Ed., Smuts, B.B., Wrangham, R.W., Cheney, D.L., Struhsaker, T.T. and Seyfarth, R.M.) University of Chicago Press, Chicago.pp. 197-209.

PARR, L.A., MATHESON, M.D., BERNSTEIN, I.S. and DE WAAL, F.B.M. 1997. Grooming down the hierarchy: Allogrooming in captive brown capuchin monkeys, Cebus apella. An. Behav. 54(2): 361-367.

RAHMAN, M.M. 2012. Feeding Biology and Nutrient Composition in Diet of Hanuman Langur (Semnopithecus entellus) in Keshabpur and Manirampur, Jessore. M.S. thesis (unpublished), University of Dhaka, Dhaka, Bangladesh.

RAJPUROHIT, D.S. and RAJPUROHIT, L.S. 2003. Dominance structure of hanuman langur (Semnopithecus entellus). Int. Ethol. Conf., Florianopolis, Brazil. pp.196.

RAJPUROHIT, D.S. and RAJPUROHIT, L.S. 2005. Displacement interactions-the determinants of dominance hierarchy in Hanuman langur, Semnopithecus entellus around Jodhpur India. J. Adv. Zool.26(2): 64-68.

ROBERTS, T.J. 1997. The Mammals of Pakistan. Revised ed. Karachi: Oxford Univ. Press. pp. 1-525.

ROONWAL, M.L. and MOHNOT, S.M. 1977. Primates of South Asia: Ecology, Sociology and Behavior. Harvard University Press, Cambridge. pp. 234-270.

SRIVASTAVA. A. and MOHNOT, S.M. 1992. Existence of multimale troops and their transformation into unimale troops in Hanuman langurs. Primate Report. 34: 71-75.

SUGIYAMA, Y. 1965. Behavioral development and social structure in two troops of Hanuman langurs (Presbytis entellus). Primates. 6(2): 213-247.

WALTERS, J. and SEYFARTH, R.M.1987. Conflict and cooperation. In: Primate Societies (Ed., Smuts, B., Cheney, D.L., Seyfarth, R.M., Wrangham, R.W. and Struhsaker, T.T.) University of Chicago Press, Chicago. pp. 306-317. 